\title{
Body mass index as an independent risk factor for inferior vena cava resection during thrombectomy for venous tumor thrombus of renal cell carcinoma
}

\author{
Bin-Shuai Wang ${ }^{1 \dagger}$, Run-Zhuo Ma ${ }^{1 \dagger}$, Yu-Qing Liu', Zhuo Liu', Li-Yuan Tao², Min Lu³, Guo-Liang Wang',
} Shu-Dong Zhang ${ }^{1}$, Jian Lu' ${ }^{1 *}$ and Lu-Lin Ma ${ }^{1 *}$

\begin{abstract}
Objective: To define preoperative clinical and radiographic risk factors for the need of inferior vena cava (IVC) resection in patients with renal cell carcinoma (RCC) and IVC tumor thrombus.

Methods: We reviewed data of 121 patients with renal cell carcinoma and venous tumor thrombus receiving radical nephrectomy and thrombectomy at our institution between 2015 and 2017, and 86 patients with Mayo I-IV level tumor thrombus were included in the final analysis. Clinical features, operation details, and pathology data were collected. Preoperative images were reviewed separately by two radiologists. Univariable and multivariable logistic regression analyses were applied to evaluate clinical and radiographic risk factors of IVC resection.

Results: Of the 86 patients, 44 (51.2\%) received IVC resection during thrombectomy. In univariate analysis, we found that body mass index $(\mathrm{BMI})$ (odds ratio $[\mathrm{OR}]=1.22, P=0.003$ ), primary tumor diameter $(\mathrm{OR}=0.84, P=0.022)$, tumor thrombus width $(\mathrm{OR}=1.08, P=0.037)$, tumor thrombus level $(\mathrm{OR}=1.57, P=0.030)$, and IVC occlusion $(\mathrm{OR}=2.67, P=0.038)$ were associated with the need for resection of the IVC. After adjusting for the other factors, BMI (OR=1.18, $P=0.019)$ was the only significant risk factor for IVC resection. Multivariable analysis in Mayo II-IV subgroups confirmed BMI as an independent risk factor $(\mathrm{OR}=1.26, P=0.024)$. A correlation between $\mathrm{BMI}$ and the width (Pearson's correlation coefficient $[P C C]=0.27, P=0.014$ ) and length $(P C C=0.23, P=0.037$ ) of the tumor thrombus was noticed.

Conclusion: We identified BMI as an independent risk factor for IVC resection during thrombectomy of RCC with tumor thrombus in a Chinese population. More careful preoperative preparation for the IVC resection and/or reconstruction is warranted in patients with higher BMI.
\end{abstract}

Keywords: Renal cell carcinoma, Venous tumor thrombus, Thrombectomy, Vascular resection, Risk factor

\section{Introduction}

Renal cell carcinoma (RCC) represents $2-3 \%$ of all cancers [1]. In the USA, RCC represents $5 \%$ of annual new cancer cases and is the third most common cancer in the urinary system [2]. In China, the incidence rate of RCC is approximately $2 \%$ of adult malignant tumors, ranking second in urological malignancies, and the incidence rate keeps rising each year [3]. One of the unique

\footnotetext{
*Correspondence: lujian@bjmu.edu.cn; malulinpku@163.com

${ }^{\dagger}$ Bin-Shuai Wang and Run-Zhuo Ma contributed equally to this work.

${ }^{1}$ Department of Urology, Peking University Third Hospital, Beijing, China

Full list of author information is available at the end of the article
}

features of RCC is venous tumor thrombus (VTT) formation, with an incidence varying from 4 to $10 \%$ among all cases [4]. The VTT could migrate from the renal vein to the inferior vena cava (IVC) and even to the right atrium.

Studies have reported that RCC with VTT leads to a 1-year disease-specific survival of $29 \%$ among untreated patients. After thrombectomy, the 5-year survival rate can increase to $40-65 \%$ [5]. Radical nephrectomy combined with thrombectomy is the only current potential curative method [6]. The survival rate of patients with tumor thrombus was better in those receiving both

(C) The Author(s). 2019 Open Access This article is distributed under the terms of the Creative Commons Attribution 4.0 International License (http://creativecommons.org/licenses/by/4.0/), which permits unrestricted use, distribution, and 
nephrectomy and tumor thrombectomy compared to patients receiving nephrectomy alone [7].

During thrombectomy, if the tumor was found with any invasion into the IVC wall, partial or circumferential resection of the IVC is preferred [8]. In this case, the risk of the surgery is generally high, as IVC resection is generally determined during the operation, without careful preoperative preparation. Preoperative prediction for the evaluation of IVC resection is required for treatment planning and patient counseling.

Previous studies have reported several radiographic predictors of the evaluation for IVC resection [9-12]. However, some of these studies are limited by the relatively small size of their cohort $[9,10]$, while others have focused on radiographic features instead of clinical characteristics $[11,12]$.

Therefore, the objective of our study was to define preoperative clinical and radiographic risk factors for IVC resection prediction.

\section{Methods and materials Patients}

After obtaining institutional review board approval, we reviewed a total of 121 cases with renal mass and VTT from January 2015 to December 2017 who received nephrectomy and thrombectomy in our institution. Exclusion criteria included (a) level 0 venous tumor thrombus (Mayo classification) [13], (b) incomplete clinical or radiographic image data, and (c) pathology type other than renal cell carcinoma. Ultimately, a total of 86 cases were included for analysis (Fig. 1).

\section{Clinical and radiographic features}

We collected clinical features, including age, gender, comorbidities, laterality, body mass index (BMI), serum creatinine ( $\mathrm{SCr}$ ), ASA score, nodal and metastasis status, and pathologic features.

Preoperative MRI or CT data were reviewed by two radiologists blind to patients' surgery information. We recorded whether the tumor thrombus totally occluded IVC by whether contrast medium could pass the IVC during arterial/venous phase. The length and width of the tumor thrombus were also measured (Fig. 2). In brief, the length of the tumor thrombus was measured by the sum of the length in the renal vein and the IVC. The maximum diameter of the tumor thrombus was measured in the coronary plane. The diameter of the IVC was measured at the superior level of the diaphragm. Then, the cohort was grouped by the ratio of the thrombus width to the IVC width. The cases with the ratio of $<2 / 3,2 / 3-1$, and $>1$ were classified into three groups.

\section{Surgical approaches and outcomes of interest}

The surgical approach of IVC tumor thrombectomy in our institution was described previously $[14,15]$. Briefly, resection of IVC was generally determined intraoperatively. If the tumor thrombus did not grossly invade the IVC wall and could be resected integrally, thrombectomy followed by cavorrhaphy with running suture was performed. If the tumor thrombus grossly invaded the IVC wall, vein resection was undertaken to ensure at least $1-\mathrm{mm}$ negative margin. After vein resection, if the remaining IVC lumen was compromised by more than half of the original diameter $[16,17]$, the reconstruction was performed using an autogenous graft patch (e.g., ipsilateral gonadal vein). In some cases, where the VTT was accompanied by the distal bland thrombus or the VTT circumferentially invaded the IVC, complete circumferential resection of the IVC was needed. In this

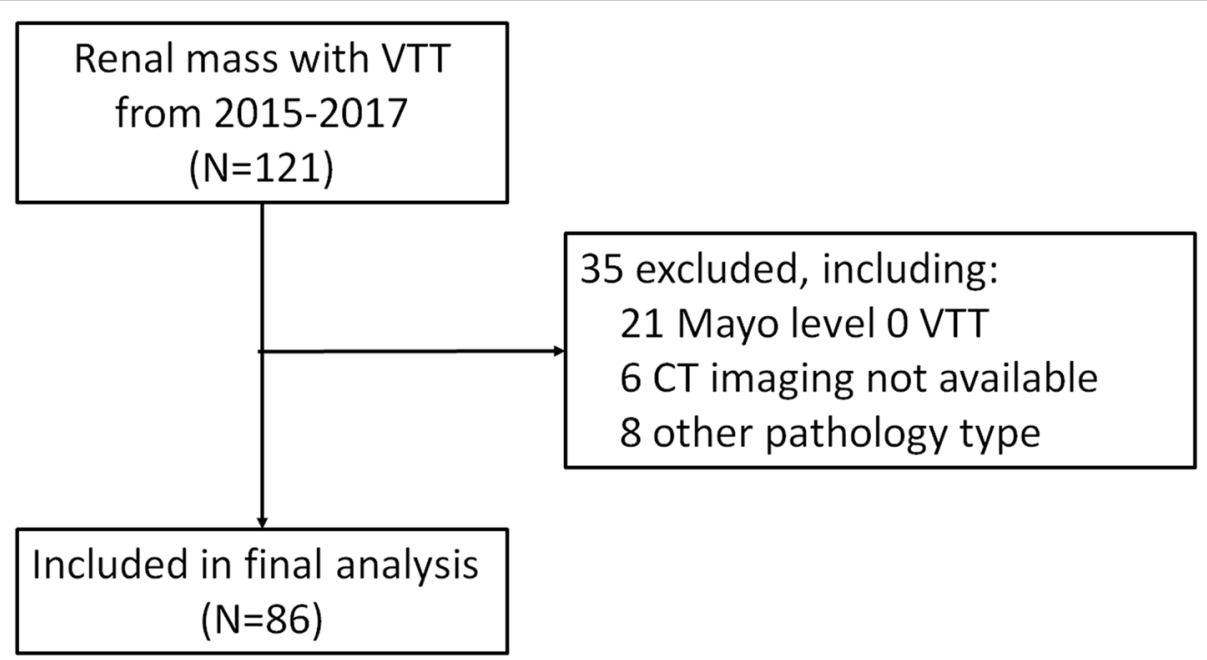

Fig. 1 Summary of our study cohort and flow chart of exclusion criteria 


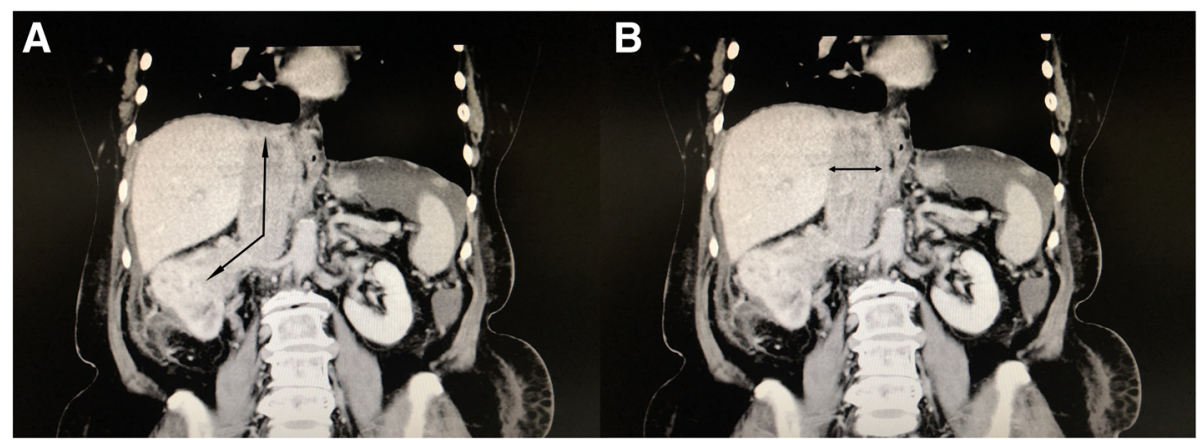

Fig. 2 Measurement of the length and width of IVC tumor thrombus. a The length is the sum of the tumor thrombus in the renal vein and in the IVC. $\mathbf{b}$ The maximum width of the tumor thrombus is measured in the coronary plane

situation, the left kidney could be left alone without renal vein reconstruction because of abundant collateralization, while the right kidney required renal vein reconstruction in order to achieve sufficient blood reflux. The primary outcome of interest was whether the IVC was resected during surgery. We defined any partial or segmental resection of the IVC during surgery as the endpoint of observation indicators.

\section{Statistical analysis}

Categorical variables were summarized with percentages, and continuous variables were summarized with medians and interquartile ranges (IQRs). Chi-squared tests and two-sample $t$ tests were applied for comparisons between groups. Univariate logistic regression analysis was used to analyze risk factors for the need of IVC resection, then significant factors were included in subsequent multivariate analysis. The results were summarized with odds ratios and 95\% confidence intervals (CIs). The correlation between two continuous variables was calculated by Pearson's correlation coefficient. The statistical tests were performed with SPSS 24.0 (IBM Inc., Chicago, IL, USA). All tests were two-sided, and $P$ values $<0.05$ were considered to be statistical significance.

\section{Results}

Clinical and radiographic features of our cohort are shown in Table 1. Among the 86 patients, 44 (51.2\%) received IVC resection. These patients were more likely to have higher BMI $\left(23.9 \mathrm{~kg} / \mathrm{m}^{2}\right.$ vs. $\left.22.0 \mathrm{~kg} / \mathrm{m}^{2}, P=0.001\right)$, smaller diameter of renal mass $(8.3 \mathrm{~cm}$ vs. $9.3 \mathrm{~cm}, P=$ $0.016)$, wider tumor thrombus in IVC $(21.5 \mathrm{~cm}$ vs. 21.0 $\mathrm{cm}, P=0.032)$, higher VTT levels $(P=0.048)$, and a higher percentage of IVC occlusion $(45.5 \%$ vs. $23.8 \%, P$ $=0.035$ ).

Univariate and multivariate associations of preoperative clinical and radiographic features predicting the need for IVC resection are shown in Table 2. Univariate analysis confirmed that the aforementioned factors were significantly associated with the resection of IVC. However, in multivariate analysis, BMI was the only factor associated with IVC resection $(\mathrm{OR}=1.18, P=0.019)$. The receiver operating characteristic (ROC) curve depicting the relationship between BMI and resection of IVC had an area under the curve (AUC) of 0.70 (Fig. 3a). The best cutoff value was $22.2 \mathrm{~kg} / \mathrm{m}^{2}$, which achieved a sensitivity of $77.3 \%$ and a specificity of $54.8 \%$.

We noticed a significant increased possibility of IVC resection in the Mayo level II-IV cohort compared to the Mayo level I cohort $(60.0 \%$ vs. $30.8 \%, P=0.013$, not shown in the tables). Therefore, we performed similar multivariate analysis in the Mayo level II-IV subgroup, and the results are shown in Table 3. BMI was still the only significant risk factor for IVC resection $(\mathrm{OR}=1.26$, $P=0.024)$. The ROC curve depicting the relationship between BMI and resection of IVC in the subgroup achieved an AUC of 0.71 (Fig. 3b). The best cutoff value was $22.4 \mathrm{~kg} / \mathrm{m}^{2}$, which achieved a sensitivity of $77.8 \%$ and a specificity of $54.2 \%$.

Furthermore, we found that BMI was significantly correlated with VTT width (Pearson's correlation coefficient $[\mathrm{PCC}]=0.27, P=0.014)$ and length $(\mathrm{PCC}=0.23, P=$ $0.037)$. The patients comorbid with hypertension $(24.8$ $\mathrm{kg} / \mathrm{m}^{2}$ vs. $\left.22.5 \mathrm{~kg} / \mathrm{m}^{2}, P=0.006\right)$ or diabetes $\left(27.1 \mathrm{~kg} / \mathrm{m}^{2}\right.$ vs. $\left.23.2 \mathrm{~kg} / \mathrm{m}^{2}, P=0.012\right)$ tended to have a higher BMI.

\section{Discussion}

The most challenging part of thrombectomy involves the resection and reconstruction of the IVC. Preoperative prediction could assist urologists in better patient counseling, reconstruction planning, and vascular surgical arranging. Therefore, we analyzed relevant clinical and radiographic features to determine the risk factors of IVC resection. In our study, 51\% (44/86) of patients underwent IVC resection. We found that BMI, primary tumor diameter, tumor thrombus width, VTT level, and IVC occlusion were significantly associated with IVC resection in univariate 
Table 1 Comparison of clinical and pathologic features by need of resection of IVC

\begin{tabular}{|c|c|c|c|c|}
\hline Feature & $\begin{array}{l}\text { In total } \\
N=86\end{array}$ & $\begin{array}{l}\text { No. of IVC resection } \\
N=42\end{array}$ & $\begin{array}{l}\text { IVC resection } \\
N=44\end{array}$ & $P$ value \\
\hline \multicolumn{5}{|l|}{ Median (IQRs) } \\
\hline Age, years & $61.0(53.8-67.3)$ & $60.5(53.8-68.0)$ & $61.0(53.3-67.0)$ & 0.383 \\
\hline $\mathrm{BMl}, \mathrm{kg} / \mathrm{m}^{2}$ & $23.1(21.1-26.1)$ & $22.0(19.4-24.3)$ & $23.9(22.3-27.7)$ & 0.001 \\
\hline Preoperative $\mathrm{SCr}$, $\mu \mathrm{mol} / \mathrm{L}$ & $97.5(83.5-113.0)$ & $92.0(78.3-113.8)$ & $102.0(89.0-112.8)$ & 0.074 \\
\hline Tumor diameter, cm & $8.4(6.9-10.4)$ & $9.3(7.1-11.3)$ & $8.3(5.8-10.0)$ & 0.016 \\
\hline Tा width, $\mathrm{cm}$ & $22.0(12.8-27.3)$ & $21.0(18.0-25.0)$ & $24.5(19.3-28.8)$ & 0.032 \\
\hline \multicolumn{5}{|l|}{$N(\%)$} \\
\hline \multicolumn{5}{|l|}{ Sex } \\
\hline Male & $61(70.9)$ & $26(61.9)$ & $35(79.5)$ & \multirow[t]{2}{*}{0.072} \\
\hline Female & $25(29.1)$ & $16(38.1)$ & $9(20.5)$ & \\
\hline \multicolumn{5}{|l|}{ Side } \\
\hline Left & $21(24.4)$ & $9(21.4)$ & $12(27.3)$ & \multirow[t]{2}{*}{0.528} \\
\hline Right & $65(75.6)$ & $33(78.6)$ & $32(72.7)$ & \\
\hline \multicolumn{5}{|l|}{ ASA score } \\
\hline 1 & $4(4.7)$ & $3(7.1)$ & $1(2.3)$ & \multirow[t]{3}{*}{0.113} \\
\hline 2 & $67(77.9)$ & $35(83.3)$ & $32(72.7)$ & \\
\hline 3 & $15(17.4)$ & $4(9.5)$ & $11(25.0)$ & \\
\hline \multicolumn{5}{|l|}{ cN stage } \\
\hline $\mathrm{cNO}$ & $41(47.7)$ & $22(52.4)$ & $19(43.2)$ & \multirow[t]{2}{*}{0.393} \\
\hline $\mathrm{cN} 1$ & $45(52.3)$ & $20(47.6)$ & $25(56.8)$ & \\
\hline \multicolumn{5}{|l|}{ cM stage } \\
\hline $\mathrm{cMO}$ & $58(67.4)$ & $25(59.5)$ & $33(75.0)$ & \multirow[t]{2}{*}{0.126} \\
\hline $\mathrm{cM} 1$ & $28(32.6)$ & $17(40.5)$ & $11(25.0)$ & \\
\hline \multicolumn{5}{|l|}{ Mayo classification } \\
\hline 1 & $26(30.2)$ & $18(42.9)$ & $8(18.2)$ & \multirow[t]{4}{*}{0.048} \\
\hline 2 & $26(30.2)$ & $12(28.6)$ & $14(31.8)$ & \\
\hline 3 & $21(24.4)$ & $6(14.3)$ & $15(34.1)$ & \\
\hline 4 & $13(15.1)$ & $6(14.3)$ & $7(15.9)$ & \\
\hline \multicolumn{5}{|c|}{ Width of thrombus/width of IVC } \\
\hline$\leq 2 / 3$ & $33(38.4)$ & $20(47.6)$ & $13(29.5)$ & \multirow[t]{3}{*}{0.225} \\
\hline $2 / 3-1$ & $38(44.2)$ & $16(38.1)$ & $22(50.0)$ & \\
\hline$>1$ & $15(17.4)$ & $6(14.3)$ & $9(20.5)$ & \\
\hline \multicolumn{5}{|l|}{ IVC occlusion } \\
\hline Yes & $30(34.9)$ & $10(23.8)$ & $20(45.5)$ & \multirow[t]{2}{*}{0.035} \\
\hline No & $56(65.1)$ & $32(76.2)$ & $24(54.5)$ & \\
\hline \multicolumn{5}{|l|}{ Pathology type } \\
\hline Clear cell & $68(79.1)$ & $36(85.7)$ & $32(72.7)$ & \multirow[t]{6}{*}{$0.139^{*}$} \\
\hline Papillary & $12(14.0)$ & $3(7.1)$ & $9(20.5)$ & \\
\hline Chromophobe & $1(1.2)$ & 0 & $1(2.3)$ & \\
\hline Ewing's sarcoma & $1(1.2)$ & $1(2.4)$ & 0 & \\
\hline Squamous carcinoma & $1(1.2)$ & 0 & $1(2.3)$ & \\
\hline Unclassified & $3(3.5)$ & $2(4.8)$ & $1(2.3)$ & \\
\hline
\end{tabular}

Furman's classification 
Table 1 Comparison of clinical and pathologic features by need of resection of IVC (Continued)

\begin{tabular}{clll}
\hline Feature & In total & No. of IVC resection & IVC resection \\
& $N=86$ & $N=42$ & $N=44$ \\
\hline $1-2$ & $29(33.7)$ & $15(35.7)$ & $14(31.8)$ \\
$3-4$ & $57(66.3)$ & $27(64.3)$ & $30(68.2)$ \\
\hline
\end{tabular}

IQRs interquartile ranges, IVC inferior vena cava, $\pi$ tumor thrombus

${ }^{*}$ Clear cell type vs. others

analysis. BMI was the only independent risk factor after adjustment for the other factors.

High BMI is a well-recognized risk factor for RCC [18]. With each additional unit of BMI, the relative risk of developing RCC increases by 1.07 times [19]. Therefore, it is not surprising to find a 1.7-fold higher relative mortality risk due to RCC in the high BMI $\left(\geq 35.0 \mathrm{~kg} / \mathrm{m}^{2}\right)$ group compared to the normal BMI $\left(18.5-24.9 \mathrm{~kg} / \mathrm{m}^{2}\right)$ group in a population-based cohort [20]. However, for patients who have already suffered from RCC, higher BMI predicts a better overall survival and cancer-specific survival conditions [21, 22]. This phenomenon has also been validated in patients with RCC and tumor thrombus [23, 24]. The paradox of the prognostic value of BMI may be partly explained by the need for extra energy to battle cancer and the endocrine function of adipose tissue [25].

Here, our study first reveals the relationship between BMI and the need of IVC resection during thrombectomy for RCC tumor thrombus. This is true in Mayo level I-IV patients and is also true when we narrowed the cohort to Mayo levels II-IV, a group that has a higher possibility of IVC resection and a greater need for risk stratification. We defined any resection of IVC wall as the outcome of interest, which is different from previous studies [9-12]. A preoperative prediction model proposed by the Mayo Clinic defined the primary endpoint as the resection of the IVC that resulted in the need of vascular reconstruction beyond primary cavorraphy [11]. The subsequent external validation study of this model adopted the same endpoint but failed to validate the model's power in a 37-case cohort [12]. It is not difficult to understand this contradiction if we take into account the possibly different reconstruction criteria between these institutions. The lack of a specific consensus on vascular reconstruction criteria might limit further generalizability of this prediction model. Other studies defined pathologic invasion of the wall of the IVC or the renal vein as the primary outcome of interests $[9,10]$. Pathologic invasion as the primary endpoint is more objective but also has its own drawbacks. It might overlook other factors resulting in the resection of the IVC wall, such as tight adherence or bland thrombus. From this point of view, we chose the need of any resection of IVC wall as the endpoint to represent the difficulty of thrombectomy. Resection might result from the direct invasion of the tumor thrombus, tight adherence between the thrombus and the venous wall, or a bland thrombus that cannot be dissected. No matter which reason, it increases the difficulty of the surgery and harbors the need of complicated reconstruction. Defining the risk factors of this endpoint can help surgeons to stratify patients preoperatively, determine which patient warrants reconstruction planning, and lower the risk of one of the most complicated urologic surgeries.

We noticed a correlation between BMI and the length $(\mathrm{PCC}=0.23, P=0.037)$ and width $(\mathrm{PCC}=0.27, \quad P=$ 0.014 ) of the tumor thrombus. This could partly explain why BMI is positively related to the IVC resection rate. Furthermore, the tendency of comorbidity of hypertension and diabetes $(P=0.006$ and 0.012 respectively), which are common vascular risk factors, may also contribute to tumor thrombus adherence or distal bland thrombus formation, which in turn increases the IVC resection rate in high-BMI patients.

Table 2 Univariate and multivariate associations of preoperative clinical and radiographic features predicting the need for IVC resection

\begin{tabular}{|c|c|c|c|c|}
\hline \multirow[t]{2}{*}{ Feature } & \multicolumn{2}{|l|}{ Univariable analysis } & \multicolumn{2}{|l|}{ Multivariable analysis } \\
\hline & Odds ratio $(95 \% \mathrm{Cl})$ & $P$ value & Odds ratio $(95 \% \mathrm{Cl})$ & $P$ value \\
\hline $\mathrm{BMI}, \mathrm{kg} / \mathrm{m}^{2}$ & $1.22(1.01-1.39)$ & 0.003 & $1.18(1.03-1.35)$ & 0.019 \\
\hline Mayo classification & $1.57(1.03-2.41)$ & 0.030 & $1.14(0.68-1.90)$ & 0.623 \\
\hline Tumor diameter, $\mathrm{cm}$ & $0.84(0.72-0.97)$ & 0.022 & $0.86(0.72-1.01)$ & 0.068 \\
\hline$\Pi$ width, $\mathrm{cm}$ & $1.08(1.01-1.17)$ & 0.037 & $1.05(0.96-1.14)$ & 0.285 \\
\hline \multicolumn{5}{|l|}{ IVC occlusion } \\
\hline No & Reference & 0.038 & Reference & 0.403 \\
\hline Yes & $2.67(1.06-6.73)$ & & $1.58(0.54-4.62)$ & \\
\hline
\end{tabular}

$\pi$ tumor thrombus 
A

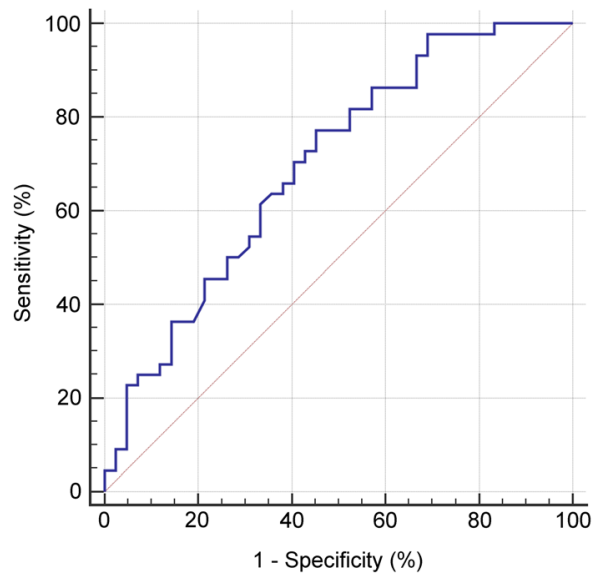

B

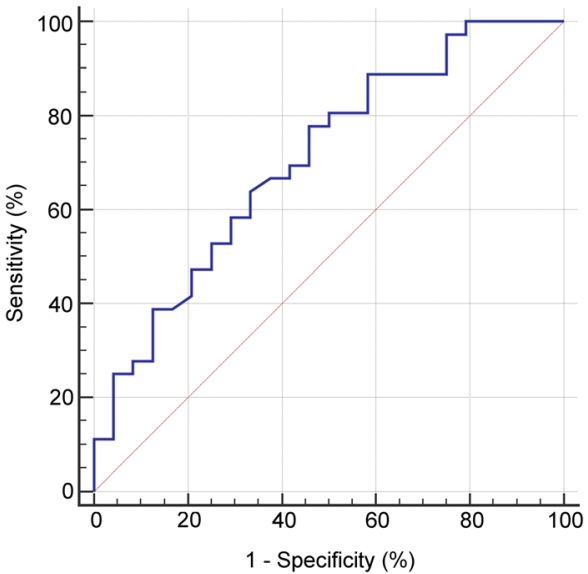

Fig. 3 ROC curve depicting the relationship between BMI and IVC resection. a ROC curve of the relationship between BMI and the IVC resection in Mayo level I-IV patients. AUC $=0.70$. The best cutoff value was $22.2 \mathrm{~kg} / \mathrm{m}^{2}$, which achieved a sensitivity of $77.3 \%$ and a specificity of $54.8 \%$. $\mathbf{b}$ ROC curve of the relationship between BMI and the IVC resection in Mayo level II-IV patients. AUC $=0.71$. The best cutoff value was $22.4 \mathrm{~kg} / \mathrm{m}^{2}$, which achieved a sensitivity of $77.8 \%$ and a specificity of $54.2 \%$

The resection rate $(51.2 \%)$ was high in our cohort. As mentioned before, we calculated the rate by any resection of the IVC wall; thus, it is natural that the rate is higher compared to the rate in the study, which only counted resections requiring complicated reconstruction (22\%) [11], or another study, which only counted the IVC interruption (25\%) [26]. We also noticed that BMI (median $23.1 \mathrm{~kg} / \mathrm{m}^{2}$, interquartile ranges [IQRs] 21.1$26.1 \mathrm{~kg} / \mathrm{m}^{2}$ ) is apparently lower in our cohort compared to western cohorts (median $26.5-29.0 \mathrm{~kg} / \mathrm{m}^{2}$ ) [23, 27, 28]. It is easy to understand this difference because of the general low BMI of Asian populations [29], but it warrants further external validation of our finding in western cohorts.

In univariate analysis, we also found primary tumor diameter, tumor thrombus width, VTT level, and IVC occlusion were associated with the resection of IVC. Though not significant after adjustment for BMI, these factors should also be considered in risk stratification. It is worth mentioning that primary tumor diameter is negatively related to the need for IVC resection (univariate analysis, $P=0.022$ ); although this needs further

Table 3 Multivariate analysis for predictors of the need for IVC resection in the Mayo II-IV subgroup

\begin{tabular}{lll}
\hline Feature & \multicolumn{2}{l}{ Multivariable analysis } \\
\cline { 2 - 3 } & Odds ratio $(95 \% \mathrm{Cl})$ & $P$ value \\
\hline BMl, kg/m² & $1.26(1.03-1.54)$ & 0.024 \\
Tumor diameter, cm & $0.84(0.68-1.04)$ & 0.107 \\
TT width, cm & $1.08(0.97-1.20)$ & 0.144 \\
IVC occlusion & & \\
$\quad$ Yes vs. No & $1.85(0.51-6.64)$ & 0.347 \\
\hline
\end{tabular}

validation, it at least proves that a large primary tumor should not be considered as a regular risk factor for IVC resection.

There are also several limitations in our study. The need for resection of the IVC lacks postoperative pathological verification due to the pathological sampling problem. However, as mentioned before, since our aim was to predict the difficulty of surgery, pathology is not a necessary endpoint. Additionally, the present study is limited by its retrospective and single-center nature. Prospective study and external validation is needed in the future.

In conclusion, we identified BMI as an independent risk factor for the need for IVC resection during thrombectomy of RCC with tumor thrombus. More careful preoperative preparation for the vascular resection and/or reconstruction is warranted in patients with a higher BMI. Further external validation is needed in western cohorts, which have higher overall BMI than our cohort.

\section{Abbreviations}

AUC: Area under the curve; BMI: Body mass index; Cl: Confidence interval; Cindex: Concordance index; IQRs: Interquartile ranges; IVC: Inferior vena cava; OR: Odds ratio; PCC: Pearson's correlation coefficient; RCC: Renal cell carcinoma; ROC: Receiver operating characteristic; SCr: Serum creatinine; VTT: Venous tumor thrombus

\section{Acknowledgements}

The authors would like to acknowledge Bin Yang, Haizhui Xia, Zhiying Zhang, and Wei He for their kind help with data collection, Dr. Rui Huang for her kind comments on paper writing, all the nurses in our center for their services, and patients involved in this study. 


\section{Availability of data and materials}

The analyzed data sets generated during the study are available from the corresponding author upon reasonable request.

\section{Authors' contributions}

BSW and RZM drafted the manuscript. YQL, ZL, ML, GLW, and SDZ collected the data. LYT analyzed the data. JL and LLM revised and proofread the manuscript. All authors read and approved the final manuscript.

\section{Ethics approval and consent to participate}

The study was approved by the ethics committees of Peking University Third Hospital. Informed consent was obtained from all individual participants included in the study.

\section{Consent for publication}

Not applicable.

\section{Competing interests}

The authors declare that they have no competing interests.

\section{Publisher's Note}

Springer Nature remains neutral with regard to jurisdictional claims in published maps and institutional affiliations.

\section{Author details}

'Department of Urology, Peking University Third Hospital, Beijing, China. ${ }^{2}$ Research Center of Clinical Epidemiology, Peking University Third Hospital, Beijing, China. ${ }^{3}$ Department of Pathology, Peking University Third Hospital, Beijing, China.

Received: 8 November 2018 Accepted: 3 January 2019

Published online: 15 January 2019

\section{References}

1. Ljungberg B, Bensalah K, Canfield S, Dabestani S, Hofmann F, Hora M, et al. EAU guidelines on renal cell carcinoma: 2014 update. Eur Urol. 2015;67:91324.

2. Siegel RL, Miller KD, Jemal A. Cancer statistics, 2018. CA Cancer J Clin. 2018; 68:7-30.

3. Chen W, Zheng R, Baade PD, Zhang S, Zeng H, Bray F, et al. Cancer statistics in China, 2015. CA Cancer J Clin. 2016;66:115-32.

4. Benkirane A, Khodari M, Yakoubi R, Lambert M, Koussa M, Ghoneim T, et al. Polytetrafluoroethylene expanded prosthesis as replacement of the inferior vena cava in renal cell carcinoma with caval thrombus. Int J Urol. 2014;21: 448-52.

5. Lambert EH, Pierorazio PM, Shabsigh A, Olsson CA, Benson MC, McKiernan JM. Prognostic risk stratification and clinical outcomes in patients undergoing surgical treatment for renal cell carcinoma with vascular tumor thrombus. Urology. 2007;69:1054-8.

6. Wang B, Li H, Ma X, Zhang X, Gu L, Li X, et al. Robot-assisted laparoscopic inferior vena cava thrombectomy: different sides require different techniques. Eur Urol. 2016;69:1112-9.

7. Berczi A, Flasko T, Szerafin T, Thomas B, Bacso Z, Berczi C. Surgical management and outcome of renal cell carcinoma with inferior vena cava tumor thrombus. Urol Int. 2017:99:267-71.

8. Gonzalez J, Gorin MA, Garcia-Roig M, Ciancio G. Inferior vena cava resection and reconstruction: technical considerations in the surgical management of renal cell carcinoma with tumor thrombus. Urol Oncol. 2014;32:34.e19-26.

9. Aslam Sohaib SA, Teh J, Nargund VH, Lumley JSP, Hendry WF, Reznek RH. Assessment of tumor invasion of the vena caval wall in renal cell carcinoma cases by magnetic resonance imaging. J Urol. 2002;167:1271-5.

10. Zini L, Destrieux-Garnier L, Leroy X, Villers A, Haulon S, Lemaitre L, et al. Renal vein ostium wall invasion of renal cell carcinoma with an inferior vena cava tumor thrombus: prediction by renal and vena caval vein diameters and prognostic significance. J Urol. 2008;179:450-4.

11. Psutka SP, Boorjian SA, Thompson RH, Schmit GD, Schmitz JJ, Bower TC, et al. Clinical and radiographic predictors of the need for inferior vena cava resection during nephrectomy for patients with renal cell carcinoma and caval tumor thrombus. BJU Int. 2015;116:388-96.
12. Overholser S, Raheem O, Zapata D, Kaushik D, Rodriguez R, Derweesh $H_{\text {, et al. }}$ Radiologic indicators prior to renal cell cancer thrombectomy: implications for vascular reconstruction and mortality. Urol Ann. 2016;8:312-6.

13. Neves RJ, Zincke H. Surgical treatment of renal cancer with vena cava extension. Br J Urol. 1987;59:390-5.

14. Liu Z, Ma LL, Tian XJ, Wang GL, Hou XF, Zhang SD, et al. Clinical experience of Mayo 0-IV tumor thrombus treated with radical nephrectomy and inferior vena cava thrombectomy. Chin J Urol. 2017;11:842-7.

15. Liu Z, Ma LL, Tian XJ, Wang GL, Zhang SD, Huang Y, et al. Radical nephrectomy and thrombectomy for Mayo clinic stage III tumor thrombus: a surgical technique and clinical experience. J Peking Univ Health Sci. 2017; 4:597-602.

16. Libertino JA, Zinman L, Watkins $E$ Jr. Long-term results of resection of renal cell cancer with extension into inferior vena cava. J Urol. 1987;137:21-4.

17. Kundavaram C, de Castro Abreu AL, Chopra S, Simone G, Sotelo R, Aron M, et al. Advances in robotic vena cava tumor thrombectomy: intracaval balloon occlusion, patch grafting, and vena cavoscopy. Eur Urol. 2016;70: 884-90.

18. Chow W-H, Dong LM, Devesa SS. Epidemiology and risk factors for kidney cancer. Nat Rev Urol. 2010;7:245-57.

19. Renehan AG, Tyson M, Egger M, Heller RF, Zwahlen M. Body-mass index and incidence of cancer: a systematic review and meta-analysis of prospective observational studies. Lancet. 2008;371:569-78.

20. Calle EE, Rodriguez C, Walker-Thurmond K, Thun MJ. Overweight, obesity, and mortality from cancer in a prospectively studied cohort of U.S. adults. N Engl J Med. 2003;348:1625-38.

21. Kamat AM, Shock RP, Naya Y, Rosser CJ, Slaton JW, Pisters LL. Prognostic value of body mass index in patients undergoing nephrectomy for localized renal tumors. Urology. 2004;63:46-50

22. Bagheri M, Speakman JR, Shemirani F, Djafarian K. Renal cell carcinoma survival and body mass index: a dose-response meta-analysis reveals another potential paradox within a paradox. Int J Obes. 2016;40:1817-22.

23. Abel EJ, Margulis V, Bauman TM, Karam JA, Christensen WP, Krabbe L-M, et al. Risk factors for recurrence after surgery in non-metastatic RCC with thrombus: a contemporary multicentre analysis. BJU Int. 2016;117:87-94.

24. Spiess PE, Kurian T, Lin H-Y, Rawal B, Kim T, Sexton WJ, et al. Preoperative metastatic status, level of thrombus and body mass index predict overall survival in patients undergoing nephrectomy and inferior vena cava thrombectomy. BJU Int. 2012;110:470-4.

25. Oreopoulos A, Kalantar-Zadeh K, Sharma AM, Fonarow GC. The obesity paradox in the elderly: potential mechanisms and clinical implications. Clin Geriatr Med. 2009:25:643-59.

26. Blute ML, Boorjian SA, Leibovich BC, Lohse CM, Frank I, Karnes RJ. Results of inferior vena caval interruption by greenfield filter, ligation or resection during radical nephrectomy and tumor thrombectomy. J Urol. 2007:178:440-5.

27. Weiss VL, Braun M, Perner S, Harz A, Vorreuther R, Kristiansen G, et al. Prognostic significance of venous tumor thrombus consistency in patients with renal cell carcinoma (RCC). BJU Int. 2014;113:209-17.

28. Gagné-Loranger M, Lacombe L, Pouliot F, Fradet V, Dagenais F. Renal cell carcinoma with thrombus extending to the hepatic veins or right atrium: operative strategies based on 41 consecutive patients. Eur J Cardiothorac Surg. 2016;50:317-21.

29. WHO Expert Consultation. Appropriate body-mass index for Asian populations and its implications for policy and intervention strategies. Lancet. 2004;363:157-63.

Ready to submit your research? Choose BMC and benefit from:

- fast, convenient online submission

- thorough peer review by experienced researchers in your field

- rapid publication on acceptance

- support for research data, including large and complex data types

- gold Open Access which fosters wider collaboration and increased citations

- maximum visibility for your research: over $100 \mathrm{M}$ website views per year

At $\mathrm{BMC}$, research is always in progress.

Learn more biomedcentral.com/submissions 